\title{
Radionuclide Lymphoscintigraphy in the Evaluation of Lower Extremity Lymphedema - Single Hospital Experience
}

\author{
Rahima Parveen, Shamim M F Begum, Nasreen Sultana, Zeenat Jabin, Khokon Kumar Nath \\ National Institute of Nuclear Medicine \& Allied Sciences, Dhaka
}

Address for Correspondences: Dr. Rahima Parveen, Medical Officer, National Institute of Nuclear Medicine \& Allied Sciences, BSMMU Campus, Email: rahimaperveen@yahoo.com

\begin{abstract}
Objective: To find out the type of pattern of obstruction in patient with lymphedema of lower extremities by Lymphoscintigraphy to evaluate.

Method: This retrospective study was carried out at the National Institute of Nuclear Medicine and Allied Sciences (NINMAS) from January 2014 to June 2014. The study included 51 patients. Lymphoscintigraphy performed by Tc-99m nano-colloid and were interpreted by expert of Nuclear Medicine Physician.
\end{abstract}

Result: Lymphoscintigraphy was done total 51patients with clinically diagnosed lymphedema (29 males and 22 females; age range 10-80 years). Seventeen patients $(33.3 \%)$ revealed normal flow in both limbs, whereas only one patients $(1.9 \%)$ consistent with primary lymphedema.

Thirty-three patients $(64.7 \%)$ consistent with secondary lymphedema, where thirty patients $(\mathbf{5 8 . 8 \%})$ revealed unilateral partial obstruction and three patient $(5.9 \%)$ had bilateral partial obstruction.

Conclusion: Lymphoscintigraphy is safe and effective for the evaluation of lymphedema in lower extremity.

Key words: Lymphoscintigraphy, nano-colloid.

\section{INTRODUCTION}

Lymphedema is the accumulation of tissue fluid in the interstitial spaces, resulting from anatomical or functional lymphatic obstruction or defective lymphatic drainage (1). Local data about the prevalence of this condition are not available, but it is estimated to affect 2 to 3 million inhabitants in the US (2). It is most common in the lower limb, about $80 \%$ of cases, but can also occur in the arms, face, trunk, and external genitalia. Lymphedema is a common and chronic lymphatic disease that is frequently misdiagnosed, treated too late, or not treated at all. Lymphedema results from impaired lymphatic transport caused by injury of the lymphatics, infection, or congenital abnormality. In this study, we found the most common causes of extremity lymphedema to be infection, lymphangitis, trauma, filariasis and post-surgical complications. Patients often suffer in silence when their primary physician or surgeon suggests that the problem is mild and little can be done. However, there are effective therapies for lymphedema that can be implemented, particularly after the disorder is characterized with lymphoscitigraphy. Lymphoscintigraphy has emerged and become the standard investigation in the evaluation of lymphedematous extremities. We reviewed our experience with the use of lymphoscintigraphy for this purpose in a single regional hospital that is National Institute of Nuclear Medicine and Allied Sciences (NINMAS).

\section{MATERIALS AND METHODS}

We retrospectively identified all the cases with lower limb lymphedema referred for lymphoscintigraphy from January 2014 to December 2014.

Clinical data: 51patients with clinically diagnosed lymphedema (29 males and 22 females; age range, 10-80 years, mean age 36.31 years) underwent radionuclide lymphoscintigraphy. The main complaint of most of the patients was swelling of the lower limbs.

\section{Methods:}

The scans were performed with a single photon emission computed tomography- (Siemens e cam). The radiopharmaceutical used in this study was Tc-99m nano-colloid. Tracer was injected subcutaneously in the webs between the first and 
second inter-digital space in both lower limbs, 37 $\mathrm{MBq}(1 \mathrm{mCi})$ per site. After subcutaneous injection of $99 \mathrm{mTc}$-nanocolloid in the first inter-digital space in both feet patients were asked to walk more than 30 minutes or massage the injection sites. Two-phase dynamic images were obtained at 5 minutes (from toes to knee) and 10 minutes (from knee to groin). Anterior static scans were obtained at 30 minutes. Delayed 2-hour wholebody scans were obtained. Images of the lower limbs and pelvis were acquired, till about one hour thereafter, to assess the flow of nano colloid along the lymphatic channels and into the inguinal and iliac groups of nodes.

Three main diagnostic points of lymphoscintigraphy in lymphedema were used in this study.

The first and most important one is whether there is increased accumulation of radiotracer in lymphatic webs and soft tissue. This pattern not only indicates the existence of lymphedema but also indicates the range and severity of the disease. The second one is, for lower limb lymphedema, whether inguinal nodes could be seen on the image. No inguinal-nodes imaged indicates a more severe state of the disease. The third one is if there are abnormal lymph nodes or lymphatics branch visible on the extremities, but this is not a specific sign in lymphedema as we found some normal cases that also showed this kind of pattern. Generally, the main criteria of scintigraphic diagnosis are whether lymphatic channels could be clearly seen and accumulated radiotracer found in the soft tissue or lymphatic webs.

\section{RESULTS}

A total 51 patients $(\mathrm{F}=22$ and $\mathrm{M}=29$ with a ratio of 1:1.6; age range 10 - 80 years) had undergone lymphoscitigraphy for lymphedema. Seventeen patients $(33.3 \%)$ revealed normal flow of the nanocolloid in both limbs, whereas only one patients $(1.9 \%)$ consistent with primary lymphedema. Thirty-three patients $(64.7 \%)$ consistent with secondary lymphedema, where thirty patients $(58.8 \%)$ revealed unilateral partial obstruction and three patients $(5.9 \%)$ had bilateral partial obstruction.

There are many normal and abnormal patterns of lymphoscintigraphy (4). Usually the normal pattern of lymphoscintigraphy was that tracer could be seen at the injection site, but less activity than that in lymphedema, along the lymphatic drainage, and in groin and iliac lymph. No radiotracer accumulated in the soft tissue or lymphatic webs, indicate normal lymphoscintigraphy (Figure 2).

Table 1: Lymphoscintigraphy findings of lymphademe of lower extrimities

\begin{tabular}{|c|c|c|c|c|}
\hline $\begin{array}{c}\text { Normal } \\
\text { Lymphatic Flow }\end{array}$ & $\begin{array}{c}\text { Unilateral Partial } \\
\text { Obstruction }\end{array}$ & $\begin{array}{c}\text { Bilateral Partial } \\
\text { Obstruction }\end{array}$ & $\begin{array}{c}\text { Primary } \\
\text { Obstruction }\end{array}$ & Total Patients \\
\hline $17(33.3 \%)$ & $30(58.8 \%)$ & $03(5.9 \%)$ & $01(1.9 \%)$ & $51(100 \%)$ \\
\hline
\end{tabular}

Figure1. Unilateral partial lymphatic obstruction.

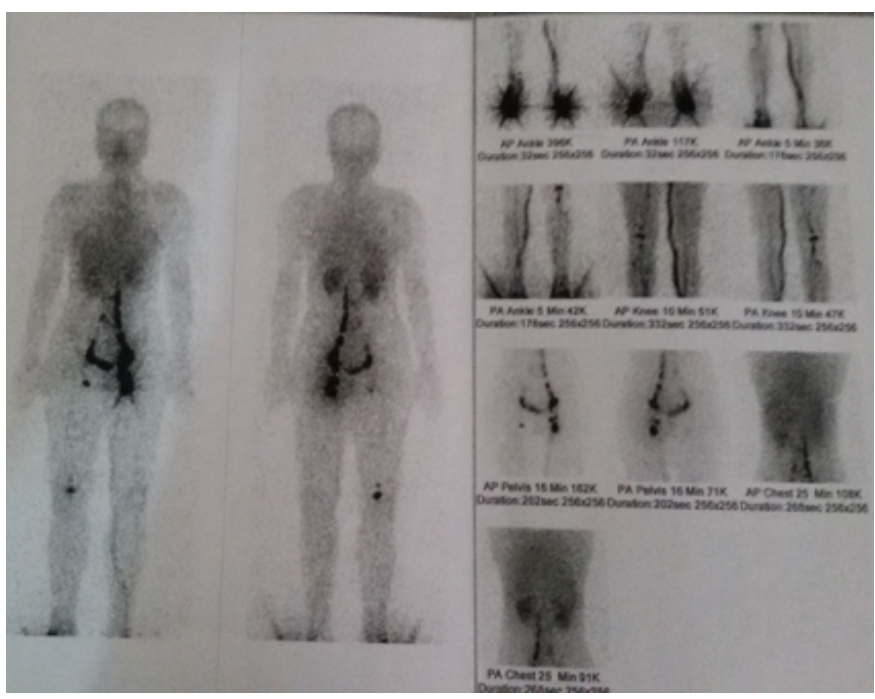

Unilateral partial obstruction (Figure 1) Several typical types of imaging characteristics were: tracer highly accumulated in the injection site, radioactivity in lymphatic drainage and groin lymph nodes could not be seen, no apparent accumulation of radiotracer in soft tissue or lymphatic webs; this pattern often suggest primary lymphedema (Figure 4). Accumulation of radioactivity in soft tissue or lymphatic webs, this was the most common pattern of lymphedema and the most important diagnostic criterion (Figure 3). 


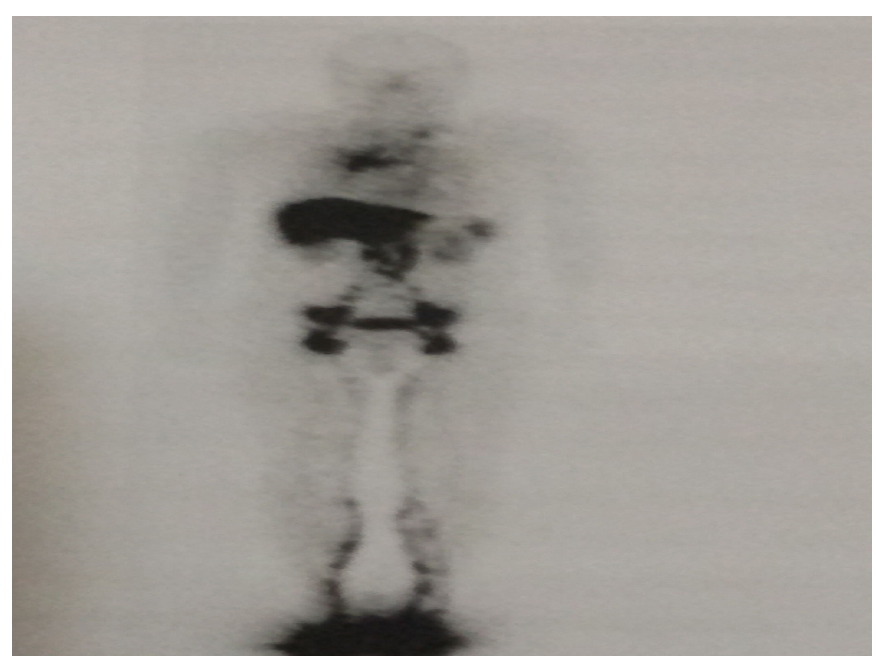

Figure 2. Normal pattern of lymphoscintigraphy.

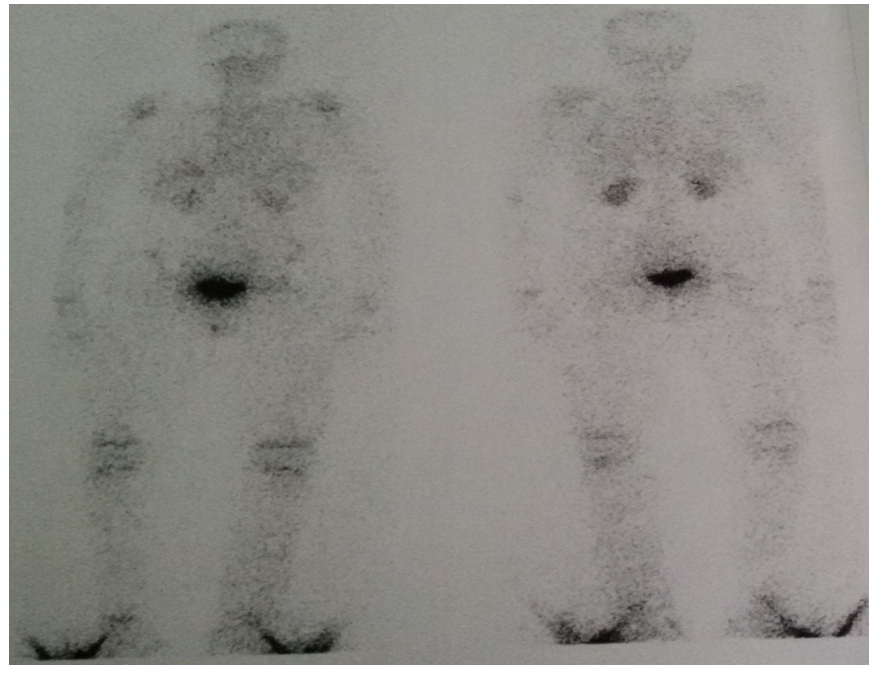

Figure 3. Primary lymphedema

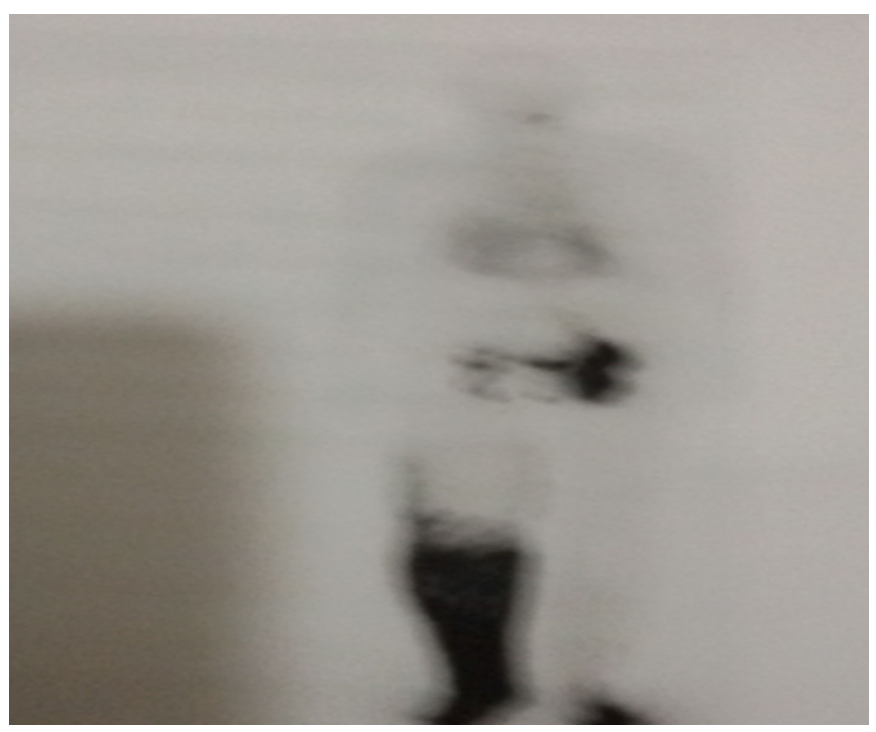

Figure 4. Soft tissue accumulation

\section{DISCUSSION}

Lymphedema of the extremities is typically a chronic disease, which is often mis-diagnosed and results in significant functional impairment, and may give rise to reduced coordination and mobility (3). Therefore, prompt and accurate diagnosis of the condition is important.

Decades ago, lymphangiography had been used to investigate lymphatic disorders, but it was a timeconsuming investigation involving direct cannulation of lymph vessels. Moreover, complications such as infections, hypersensitivity, oil embolism, and lymphatic obstruction were reported (4). Lymphoscintigraphy has replaced lymphangiography and become the investigation of choice. Its advantages include being non-invasive, free from adverse effects, and low radiation exposure to patients. Furthermore, it can be repeated and can even be used to follow-up after treatment response. The reported sensitivity and specificity of lymphoscintigraphy is approximately 66 to $100 \%$ and 83.5 to $99 \%$, respectively (5).

Lymphedema can usually be diagnosed clinically. The differential diagnosis of suspected lowerextremity lymphedema includes obesity, chronic venous insufficiency, Milroy's disease and systemic diseases (e.g., hypo-albuminaemia). Lymphoscintigraphy enables confirmation of the diagnosis in unclear cases, assessing the risk of developing lymphedema predicting the outcome of therapy and assessing the results of lymphedema treatment (6-8).

Lymphedema is found in both sexes. In this study more male are investigated than female. Cambria, et al (1993) found women are investigated for this disease more often than men (9). It can be seen at any age as already noted.

Total 51 lymphedema patients were taken in this study. Patients were undergone lymphoscintigrapy and the findings were seventeen patients (33.3\%) show normal flow of the nano-colloid in both limbs, whereas only two patients $(3.9 \%)$ consistent 
with primary lymphedema. Thirty-three patients $(64.7 \%)$ consistent with secondary lymphedema. Thirty patients $(58.8 \%)$ revealed unilateral partial obstruction, which is similar to the study of Zhibin Yuan et al (2006) (10). Only three patients (5.9\%) had bilateral partial obstruction and bilateral total occlusions are found also about 1 patient (1.9\%).

Injection of radiolabeled tracers with subsequent gamma camera monitoring has been used to study the lymphatic system since the 1950's (11).

\section{CONCLUSION}

Lymphoscintigraphy is widely considered to be the main investigation to establish the diagnosis of lymphoedema and visualize peripheral lymphatics. The technique has been refined over the past few decades and has proved reliable and reproducible. Lymphatic flow and sites of lymphatic drainage can readily be evaluated with lymphoscintigraphy, and this imaging can play a vital role in defining the etiology of lower extremity swelling and in predicting the success of common therapies. So, it is effective, safe, non-invasive and physiological method for the evaluation of lymphedema in lower extremity and giving either morphological or objective functional information useful to clinical lymphologists.

\section{REFERENCES}

1. Ter SE, Alavi A, Kim CK, Merli G. Lymphoscintigraphy. A reliable test for the diagnosis of lymphedema. Clin Nucl Med 1993;18:646-54.

2. Rockson SG, Rivera KK. Estimating the population burden of lymphedema. Ann N Y Acad Sci 2008; 1131:147-54.

3. Szuba A, Shin WS, Strauss HW, Rockson S. The third circulation: radionuclide lymphoscintigraphy in the evaluation of lymphedema. $\mathrm{J} \mathrm{Nucl} \mathrm{Med}$ 2003; 44: 43-57.

4. Nawaz K, Hamad MM, Sedek S, Awdeh M, Eklof B, AbdelDayem HM. Dynamic lymph flow imaging in lymphedema: Normal and abnormal patterns. Clin Nucl Med 1986; 11:653-658.
5. Bourgeois P. Critical analysis of the literature on lymphoscintigraphic investigations of limb edemas. Eur J Lymphology Relat Prob 1996; 6:19.

6. James WD, Berger TG, Elston DM, Odom RB, editors. Andrews' diseases of the skin: clinical dermatology. Philadelphia: Saunders Elsevier; 2006: 849.

7. Bourgeois $\mathrm{P}$, Leduc $\mathrm{O}$, Leduc A. Imaging in the management and prevention of post therapeutic upper limb edema. Cancer 1998; 83(12 Suppl American):2805-13.

8. Szuba A, Strauss W, Sirsikar SP, Rockson SG. Quantitative radionuclide lymphoscintigraphy predicts outcome of manual lymphatic therapy in breast cancer-related lymphedema of the upper extremity. Nucl Med Commun 2002; 2:1171-5.

9. Cambria RA, Gloviczki P, Naessens JM, Wahner HW. Noninvasive evaluation of the lymphatic system with lymphoscintigraphy: a prospective, semi quantitative analysis in 386 extremities. $J$ Vas Surg1993; 18: 773-782.

10. Z, Hankui L, Ruisen Zhu. The role of radionuclide lymphoscintigraphy in extremity lymphedema. $H$ K Med J 2013;20:341-344.

11. Sage HH, Gozun BV. Lymphatic scintigrams: a method for studying the functional pattern of lymphatics and lymph nodes. Cancer 1958; 11: 200-203. 